\title{
La situación de la Iglesia católica en los años 1914-1916 en una carta que nunca llegó al papa
}

\author{
Juan González Morfín
}

(Presentación y traducción)

UNIVERSIDAD PANAMERICANA, jgonzalezmorfin@yahoo.com.mx

\begin{abstract}
n hojas tamaño oficio de papel grueso y de buena clase, muy lejano del corrientemente usado para hacer copias, se encuentra en una carpeta del Archivo de la Arquidiócesis de Guadalajara un extensa carta en latín, escrita a máquina a dos tintas, negra y roja (ésta mínimamente usada y sólo para resaltar algunas frases), en perfecto estado de conservación, firmada por el arzobispo primado de México, José Mora y del Río, ${ }^{1}$ aunque no dirigida al arzobispo de Guadalajara (en esos momentos ausente de
\end{abstract}

${ }^{1}$ José Mora y del Río nació en Pajacuarán, en 1854. Fue ordenado sacerdote en la diócesis de Zamora. Más tarde, obispo de Tehuantepec, Tulancingo, León y México. Promotor de la doctrina social de la Iglesia a través de dietas y congresos católicos. A causa de esto, fue visto con recelo por las autoridades revolucionarias y, más aún, por un supuesto apoyo -que siempre negó-al régimen golpista de Victoriano Huerta. Permaneció desterrado entre 1914 y 1918. En su calidad de arzobispo primado de México, fue elegido por el delegado apostólico Mons. Jorge José Caruana, en abril de 1926, para encabezar un Comité de Obispos que, de manera colegial, intentarían buscar soluciones ante las restricciones legales para la práctica de la religión que, iniciadas con la Constitución del 17, se habían agudizado bajo el régimen del general Calles. Sus declaraciones a un diario en febrero de 1926 fueron utilizadas para justificar un recrudecimiento en la aplicación de las leyes antirreligiosas que ya existían y la aparición de nuevas disposiciones en contra de la libertad religiosa. Aunque falleció en 1928, desde 1927 se había visto obligado a dejar en manos de Mons. Ruiz y Flores y Mons. Pascual Díaz todos los asuntos del Comité Episcopal, a causa de su falta de salud y la tristeza propia del destierro. Murió en San Antonio, Texas ( $c f r$. Juan González Morfín, Los obispos y la persecución religiosa en México (Guadalajara: Universidad Panamericana, 2013), 5-20. 
su diócesis), ni tampoco al vicario general en funciones, sino al papa Benedicto XV. ${ }^{2}$

¿Por qué se encuentra este documento, al parecer original, en un archivo de Guadalajara y no de Roma? La respuesta parece encontrarse en un hecho bastante sencillo: la carta, enviada a Orozco y Jiménez ${ }^{3}$ en agosto de 1916 para que sirviera de intermediario y la hiciera llegar al papa, llegó cuando el arzobispo de Guadalajara estaba en los Estados Unidos y no en Roma, pues, secretamente había regresado a Nueva York en junio de ese año con la finalidad de ingresar a México y, clandestinamente, residir de nueva cuenta en su diócesis. Sea porque Orozco haya guardado completo silencio sobre su retorno, sea porque las comunicaciones en aquella época no siempre llegaban muy rápido, el hecho es que el señor Mora y del Río envió a Roma una carta que sólo recibiría Orozco y Jiménez algunos meses después, cuando ya estaba en América y poco podía hacer para entregarla al pontífice romano.

En cualquier caso, se trata de un extenso informe escrito, enviado desde San Antonio, Texas, que da razón detallada de algunos sucesos conocidos y otros menos conocidos, y que cita otros nueve documentos, probablemente enviados como anexos, los cuales por desgracia no se encuentran con la carta.

La epístola está redactada en un tono bastante apologético en relación con la actitud de los obispos expatriados, puesto que el autor se dedica a explicar y justificar la ausencia de los pastores mexicanos de sus diócesis a causa del estado de zozobra en que se encontraba el país y, de manera particular, se puede ver en el documento también

${ }^{2}$ Cfr. José Mora y del Río, Carta a Benedicto XV, 5-vin-1916, en Archivo de la Arquidiócesis de Guadalajara (desde ahora, AAG), sección gobierno, serie obispos: Francisco Orozco y Jiménez, años 1912-1918, sin número de folio.

${ }^{3}$ Francisco Orozco y Jiménez nació en Zamora, en 1864. Obispo de Chiapas de 1902 a 1912, y arzobispo de Guadalajara de 1913 a 1936. Junto con los demás obispos mexicanos se tuvo que exiliar en 1914 y, con riesgo de perder la vida reingresó al país en 1916. Más tarde, durante los tres ańos que duró la guerra cristera, periodo en el que fueron asesinados muchos sacerdotes, Mons. Orozco no quiso abandonar su diócesis y permaneció todo el tiempo escondido entre sus feligreses. Al pactarse el modus vivendi tuvo que exiliarse en los Estados Unidos. Regresó a su diócesis y murió en Guadalajara en 1936 (cfr. Juan González Morfín, op. cit., pp. 57-68). 
una especie de autodefensa de las imputaciones que se habían venido haciendo a la persona de Mora.

El antecedente inmediato que motivó esa larga redacción, según explica él mismo, fue una carta de parte del delegado apostólico, escrita en junio de 1916 y recién recibida por la mayoría de los prelados mexicanos, recriminándoles que prolongaran su exilio cuando la situación del país ya les permitía regresar y el alejamiento de sus sedes episcopales era causa de escándalo para sus fieles. Ante este reclamo, Mora y del Río alude a la hostilidad del gobierno también en las actuales circunstancias, explica cómo se fueron dando las expulsiones de cada uno de los obispos desterrados, revela el monto de las exacciones sufridas por algunos de ellos, así como no pocos atropellos, y explica cómo la ausencia forzada de los obispos, además de salvaguardar sus vidas, ha sido un mal menor para el pueblo fiel que, de otra manera, hubiera tenido que seguir cediendo a las extorsiones a cambio de respetar a la persona del obispo en cuestión, como ya había ocurrido. ${ }^{4}$

De diversas maneras el autor muestra que no fue una decisión unilateral, sino aprobada por el pueblo y por el clero y que, en las circunstancias reinantes, sigue siendo necesaria. Aprovecha para hacer un recuento de las falsas acusaciones que se han levantado contra los obispos y particularmente en su contra, como la de haber ayudado a Victoriano Huerta, haber participado en la conspiración que derrocó a Madero, haber reconocido a Huerta como presidente tanto él como el clero...

En relación con esto último, es interesante la manera como explica Mora y del Río que no es el clero ni el episcopado quien tiene la función de reconocer la legalidad o legitimidad de un presidente, sino, en primer lugar, las cámaras de diputados y senadores, luego, los gobernadores de los estados, y finalmente los gobiernos extranjeros. En relación con Huerta, lo reconocieron ambas cámaras, todos los gobernadores salvo dos, y la mayoría de las potencias extranjeras,

${ }^{4} \mathrm{Al}$ respecto véase Yolanda Padilla Rangel, "Anticlericalismo carrancista y exilio católico a Texas, 1914-1919”, en El anticlericalismo en México, ed. Franco Saverino y Andrea Mutolo, 449-471, sp., 453-459. México: Cámara de Diputados, itesm, M. A. Porrúa, 2008. 
mas no así el episcopado, a quien no le queda otra que atender las exigencias de cualquiera que sea la autoridad constituida.

Independientemente de su intención apologética, la carta resulta muy interesante por los datos que aporta; por ejemplo, el arzobispo reconoce haber ayudado al gobierno de Huerta una única vez, con un préstamo de 17,000 pesos en monedas de plata, después de consumado el golpe y sólo para pagar al ejército que amenazaba con amotinarse y saquear la ciudad por falta de paga. Además, buscando reivindicar su papel de Primado de México, el señor Mora se ve en la necesidad -y la cumple- de dar razón de cuál ha sido la situación de cada uno de los obispos mexicanos. ${ }^{5}$

En este sentido, el documento es un recuento único de pormenores de lo que ocurrió a la mayoría de los obispos, así como de datos puntuales sobre la persecución que se vivía en esos días. También, por haber sido escrito antes de que tuviera lugar el Constituyente de Querétaro, aporta una visión interesante de cómo veía venir los acontecimientos la jerarquía católica, en vísperas de que comenzara a sesionar el congreso que otorgaría al país una nueva Constitución.

Algunos datos que contiene son ya conocidos, otros no tanto, como el trato respetuoso y amable que utiliza Mora para hablar de Madero, la honestidad al abordar los temas relacionados con Huerta, las cantidades que se pidieron a cambio de respetar la vida de al-

${ }^{5}$ Aunque en este momento todavía el señor Mora trata de ejercer un papel de interlocutor en nombre de los obispos, quizá por su lentitud para dar respuesta puntual a las situaciones de emergencia, o tal vez por su falta de liderazgo, pronto se vería rebasado por otros obispos, por ejemplo, don Leopoldo Ruiz y Flores que, junto con Mons. Plancarte, promueve la publicación de una pastoral colectiva protestando contra algunos artículos de la Constitución; por don Francisco Orozco y Jiménez, en relación con el apoyo que a través de Mons. Francis C. Kelley prestaron los obispos estadounidenses; y por don Eulogio Gillow, quien buscaba una vía de entendimiento con Carranza que no fuera la de la confrontación (cfr. Leopoldo Ruiz y Flores, Recuerdo de recuerdos (México: Buena Prensa, 1942), 72; Marta Eugenia García Ugarte, "Debilidades y fortalezas de los obispos mexicanos durante la Revolución [1910-1914]", en Libro Anual de la Sociedad Mexicana de Historia Eclesiástica IV (2010). La Iglesia en la Revolución Mexicana (México: Minos III Milenio, 2011), 16 y 23-25; Juan González Morfín, "El Archivo Secreto Vaticano: una ventana a la historia de México", Boletín Eclesiástico, año cxxıI (10) (2011): 20-33; Asv, Archivio della Delegazione Apostolica in Messico, fasc. 108, p. 130. 
gunos obispos, la seguridad manifestada por el primado de México en relación con el hecho de que la información tergiversada que ha llegado a la sede romana proceda del señor Paredes, quien con el apoyo de los revolucionarios ejercía el cargo de vicario general de la arquidiócesis de México.

Por otro lado, el elenco que da en espańol, al final de la carta, para ubicar disposiciones legales de carácter persecutorio, es también novedoso y sirve al historiador para rastrear esas huellas de lo que fue también la reducción del campo de actuación de la Iglesia a través de las leyes.

En cuanto a la manera como expone su argumento, cabe decir que, aunque obedece a una idea unificadora de fondo (defender la actuación de los obispos expatriados), muchas veces no guarda un orden previsible, ni siquiera dentro de un mismo párrafo, por lo que se entremezclan datos (eso sí, todos con el fin de hacer ver lo complicado que hubiera sido para cualquier obispo el retornar a México en aquellas condiciones).

Se presenta ahora la versión en latín de la citada carta con la correspondiente traducción al castellano al lado, para que sea más fácil comparar con el original. Al final de la carta, se transcribe una lista de documentos que, al parecer, la acompañaban en calidad de anexos. He aquí el documento:

\section{BEATISSIME PATER:}

Josephus Mora y del Rio, Archiepiscopus Mexicanus, ad pedes Sanctitatis Tuae humillime provolutus, sequentia pro Ecclesiae animarum bono, SANCTITATIS TUAE, reverenter exponit.

Nimirum Episcopi Mexicani, qui duobus abhinc annis ob publicam rerum subvertionem extra dilectam Patriam inveniuntur, sub finem elapsi mensis Junii lit-
Santísimo Padre:

José Mora y del Río, Arzobispo de México, se dirige humildemente a los pies de Vuestra Santidad, en razón del bien de la Iglesia, de las almas y de DE VUESTRA SANTIDAD, y expone reverentemente:

Efectivamente, los obispos mexicanos, que desde hace dos años se encuentran fuera de nuestra amada Patria a causa de la subversión pública de las cosas, a 
teras acceperunt ab Excmo. Dno. Delegato Apostolico, quarum hic exemplar adjungo.

Harum equidem, BEATISSIME PATER, tenor litterarum, necnon privatorum notitiae ad eos delatae, non parum eorum animos anxios reddidit; seipsos enim accusatos dignoscunt quasi minus recte se gessissent, oves absque Pastore relinquissent, tempore adeo adverso atque aerumnis et calamitatibus omnibus pleno; iidem insuper arguuntur quod, protracta nimis eorum absentia, multum existimationis apud suos fideles amiserint; quin adhuc quod ipsa eorum voluntaria absentia eorum conditionem difficiliorem reddat coram hodiernos Mexicanos rei publicae Moderatores, ac denique quod illorum in Americae Statibus Foederatis commoratio, ansam praebeat ipsis fidelibus ad ipsos episcopos saltem veluti fautores habendos huius bellici motus, qui interventus dicitur, et Mexico imminere ex Americana Foederatione nunc conspicitur.

Haec referam Sanctitati Tuae. Archiepiscopi Angelopolitanus, de Linares et de Guadalajara necnon Episcopi S. Ludovici Potosi, de Chihuahua, Aguascalientes, fines del pasado mes de junio recibieron las cartas del Excelentísimo Señor Delegado Apostólico de las que adjunto un ejemplar.

Ciertamente, SANTÍSIMO PADRE, el tenor de estas letras, así como las noticias que les llegaron de algunos particulares, contribuyó no poco a exaltar sus ánimos, como si hubieran sido poco rectamente acusados ellos mismos de haber dejado las ovejas sin Pastor, en medio de un tiempo adverso y todo lleno de desastres y calamidades; además, éstos [acusadores] argumentan que, habiéndose prolongado tanto su ausencia, han perdido el aprecio de sus fieles; también afirman que esta voluntaria ausencia dificulta todavía más su posición ante los actuales gobernantes de México y, finalmente, que la permanencia de los obispos en los Estados Unidos da motivo a los mismos fieles de que los consideren como instigadores de la posible intervención armada de parte de la Unión Americana que, hoy por hoy, en México se ve inminente.

Paso ahora a contar a Vuestra Santidad acerca de los arzobispos de Puebla, de Linares y de Guadalajara, así como del obispo de San Luis Potosí, del de Chihuahua, 
Saltillo, de Sinaloa y de Zacatecas in Mexicana urbe convenerant, ceteris iam tunc circa communicationem impeditis: ibique certiores facti de gravissimis malis quae imminebant, quibus iam plures ex eis perpessi fuerant, de communi consilio, probantibus prudentioribus viris, tum ex clero, tum ex saeculari coetu, necnon pluribus ex Oratoribus exterarum Nationum, urbem Mexicanam primo reliquerunt, ac Veracruz, portum mexicanum, locum tunc neutralem, petierunt; deinde ab eo portu, duo ex pradictis, qui expensis solvendis haud impares erant, Europam, alii vero in proximiores hos Status Foederatos se contulerunt, habita ratione ut prope essent suis dioecesibus.

Episcopus de Chiapas, hospes in Guatimala, ex monitionibus Supremi illius Reipublicae Moderatoris, inde exire coactus huc pervenit.

Archiepiscopus de Durango a Patria discessit expulsus per vim, postquam ter captus fuerat, carcere detentus, ac pecuniae summa punitus. Idem ferme circa Episcopos de Tabasco et de Campeche. del de Aguascalientes, del de Saltillo, del de Sinaloa y del de Zacatecas, reunidos en la ciudad de México y ya entonces impedidos de entrar en comunicación con los demás. Ahí, absolutamente ciertos de los gravísimos males inminentes, que ya algunos habían experimentado, de común acuerdo, una vez que fue aprobado tanto por los más prudentes varones del clero y del pueblo fiel, como por no pocos de los funcionarios de naciones extranjeras, dejaron la ciudad de México y se trasladaron al puerto de Veracruz, lugar en ese momento neutral; luego, de ese puerto, dos que consiguieron buenas condiciones para pagar su pasaje, marcharon a Europa; los otros, en cambio, a los lugares más próximos de los Estados Unidos, con tal de estar más cerca de sus diócesis.

El obispo de Chiapas, hospedado en Guatemala, por advertencia del jefe supremo de aquella República se vio obligado a salir de ahí.

El arzobispo de Durango fue expulsado por la fuerza de su patria después de haber sido capturado tres veces, encerrado en la cárcel y castigado con una pena pecuniaria. Lo mismo los obispos de Tabasco y Campeche. 
Archiepiscopus Mechoacanensis post duos menses, a capta sua dioecesi, et postquam plus quam viginti sacerdotes loci $\mathrm{Ce}-$ laya, ubi sese caelare tenebatur, vexati ac direpti exilio tándem mulctati in Status Foederatos asportati fuerunt, ipse etiam, multis exantlatis laboribus ac difficultatibus, huc etiam commeare debuit.

Episcopus de Tulancingo, Europam petierat SS. Liminum Visitationis causa, ac in Patriam rediens, quum insulam Cuba appulisset, monitus diligenter fuit ut ab introitu abstineret.

Idem mihi accidit, postquam meam SS. Liminum Visitationem confeceram, eandem insulam attingens, monitus vehementer a missis nuntiis fui, ut ab inito proposito ulterius progrediendi deflecterem.

Hic notandum autumo quod, omni civili ordine in Mexicana Republica suppresso, non modo initio huius publicae convulsionis, sed adhuc etiam, elapsis iam duobus annis, vel legales ita quaedam formae in gubernii actibus desideratur ut incassum formale aliquod decretum exilii in Episcopos desideraretur; factis ipsis amplissime illud supplentibus. Hinc
El Arzobispo de Michoacán, después de dos meses de haber sido sacado de su diócesis, y después que más de veinte sacerdotes en Celaya, donde se había tenido que ocultar, fueron vejados, despojados y finalmente transportados al exilio, luego de muchos trabajos y dificultades, también tuvo que salir de aquí.

El obispo de Tulancingo, que se había trasladado a Europa por la Visita ad limina, en el momento en que regresaba a su patria, cuando desembarcó en la isla de Cuba, fue diligentemente advertido que se abstuviera de entrar al país.

Lo mismo me ocurrió a mí, después de realizar mi Visita ad limina, encontrándome en la misma isla, fui advertido con vehemencia por embajadores que me enviaron, que me apartara de mi propósito de entrar al país.

Hay que hacer notar que todo orden civil ha sido suprimido en la República mexicana no sólo al principio de esta convulsión pública, sino incluso ahora que ya han pasado dos años, o sea que de tal modo han desaparecido las formas legales en la actuación del gobierno, que para nada ha sido necesario un decreto formal de destierro cuando con los hechos 
Episcoporum e suis diocesibus, vera et incredibili animorum et armorum conflagratione affectis, iniqua perturbatio, durissimo exilio aequiparanda est.

Quae enim eventura erant, quaeque in deliciis habebat hoc Gubernium, publice vocitabatur; ut mense julio anni 1914 legebatur inter alia, in publico folio "EL BONETE": "Queremos perseguir la bandada de Buitres con sotana, hasta aniquilarla y confundirla; hasta dejarla impotente, exánime muerta. No queremos solamente derrotarla: queremos acabar con ella; no queremos humillarla simplemente, queremos extinguirla; no queremos que capitule, podría resurgir; queremos desaparecerla para siempre; no queremos conformarnos con que abandone el territorio de México, tenemos que perseguirla por el orbe hasta finalizar con ella. Es guerra a muerte, sin cuartel, sin misericordia y sin perdón”. Hoc autem folium tamquam Gubernii praeco edebatur.

Quod autem timor malorum in deterius futurorum, tum ipsis episcopis, tum Clero et populo ipsi, si in manibus impiorum hominum illi incidissent, haud capto consilio alio commeandi, probatis rationibus niteretur, pa- éste ha sido ampliamente suplido. De aquí que esta inicua revuelta que ha separado a los obispos de sus diócesis debe ser equiparada a un durísimo exilio.

Lo que había de venir y que ya saboreaba este gobierno era públicamente anunciado, como se podía leer, entre otros, en el folleto titulado El Bonete, publicado el mes de julio de 1914: "Queremos perseguir la bandada de Buitres con sotana, hasta aniquilarla y confundirla; hasta dejarla impotente, exánime muerta. No queremos solamente derrotarla: queremos acabar con ella; no queremos humillarla simplemente, queremos extinguirla; no queremos que capitule, podría resurgir; queremos desaparecerla para siempre; no queremos conformarnos con que abandone el territorio de México, tenemos que perseguirla por el orbe hasta acabar con ella. Es guerra a muerte, sin cuartel, sin misericordia y sin perdón". Este folleto se editaba como portavoz del gobierno.

Existía aquel temor de que los males futuros serían peores, tanto para los obispos como para el clero y el pueblo, si aquéllos [los obispos] llegaran a caer en manos de hombres impíos, no habiendo recibido otro consejo que el de 
tuit deinde exemplo plurium Episcoporum. Praeter ea quae superius relata sunt, addendum quod Episcopus Zamorensis graviter oppresus magnam pecuniae vim (duodeviginti scutatorum) solvere exactus est. Episcopus de Zacatecas, gravissimam, pro modulo suo ut solveret, quindecim millium scutatorum summam, commodato accepit, superadditis atrocibus vexationibus, et in vitam ipsam periculis, quae vix evadere potuit. Episcopus de Tepic, pro quo a fidelibus ingens etiam pecuniae summa solvi debuit, per octo menses, sed damnatus ad octo annos, vitam aegre in carcere publico, inter ipsos facinerosos homines, agebat, et fortuito liber, ab alia factione capta civitate; nunc autem, expulsis e dioecesi omnibus sacerdotibus, domi [sic] suae detinetur impeditus absolute circa dioecesis administrationem. Idem ferme dicendum circa Episcopum Colimensem. Episcopus de Tehuantepec carcerem etiam Guadalajarae cum centum aliis sacerdotibus tulit, et ipsorum libertate centum millia scutatorum soluta sunt; deinde ipse per multum tempore celatus remansit. Episcopi Campechensis et de Tabasco multas vexationes et ludibria perpessi in suis dioecesibus; marcharse, evidente por probadas razones y al que se accedió después, por el ejemplo de muchos obispos. Luego de estas cosas que han sido narradas, se debe añadir que el obispo de Zamora, amenazado de muerte, fue obligado a pagar un rescate de dieciocho mil pesos. El obispo de Zacatecas, una vez sufridas atroces vejaciones y peligros para su vida de los que apenas pudo salvarse, también tuvo que entregar, según sus posibilidades, un préstamo de quince mil pesos. El obispo de Tepic, por el que también tuvo que ser pagada por sus fieles una ingente suma de dinero, estuvo preso por ocho meses en una cárcel pública, rodeado de facinerosos, y si resultó libre fue por una causa fortuita, al ser capturada esa ciudad por una facción enemiga, ya que había sido condenado a ocho ańos de prisión. Mas ahora, habiendo sido expulsados de su diócesis todos los sacerdotes y mantenido alejado de su casa, se halla impedido absolutamente de establecer su administración cerca de la diócesis. Lo mismo el obispo de Colima. El obispo de Tehuantepec fue llevado a la cárcel de Guadalajara con otros cien sacerdotes y por su libertad se tuvieron que pagar cien mil pesos; después per- 
expulsus autem ille, post longa itinera et labores huc pervenit; hic autem ex sua dioecesi avulsus ad incognita adhuc nobis loca pervenit. Nullam autem notitiam habuimus circa Episcopos Zamorensem et de Huajuapam de Leon. Alii vero, de quibus certam habemus notitiam, occulti usque ad praesens remanent, et extra suam dioecesim; nimirum Archiepiscopus Angelopolitanus, hactenus occultus et postremo hoc tempore perquisitus: qua ratione sic se ferme gerit Episcopus de Veracruz, primo publice vexatus et detrusus in carcerem, dein favore quodam Guberni prosecutus, nunc per vim avulsus a sua dioecesi, misere vitam agere alibi tenetur; iisdem ferme conditionibus inveniuntur Episcopi Leonensis, Zamorensis, Cuernavacensis et de Chihuahua.

Ceteri autem ex Mexicanis Episcopis apud exteras gentes degentes, praecipue in Statibus Foederatis solo haud mexicanis grato, misere, licet christiana caritate fulti, nullo excepto, et aegre vitam trahentes, hic ex proborum maneció oculto por mucho tiempo. El obispo de Campeche y el de Tabasco sufrieron vejaciones y ludibrio en sus diócesis; el primero fue expulsado y consiguió llegar aquí después de muchas fatigas y un largo camino; el segundo, retirado de su diócesis, se encuentra en algún lugar todavía ahora desconocido por nosotros. Ninguna noticia tenemos de los obispos de Zamora y de Huajuapan de León. Pero los otros, de los que tenemos alguna noticia, permanecen ocultos hasta ahora y fuera de su diócesis. En efecto, el arzobispo de Puebla, se ha mantenido oculto y perseguido todo este tiempo; el de Veracruz fue primeramente arrojado a la cárcel y públicamente vejado, después, mantenido en custodia como un favor del Gobierno y, ahora, por la fuerza separado de su diócesis y obligado a vivir miserablemente en otro lugar; en las mismas condiciones se hallan los obispos de León, Zamora, Cuernavaca y Chihuahua.

El resto de los obispos mexicanos continúan en naciones extranjeras, especialmente en los Estados Unidos, lo que no es agradable para los mexicanos y, aunque sin excepción han sido sostenidos por la caridad cristiana, llevan 
etiam votis fidelium optatis passim expressis, detinentur hactenus.

Haec omnia autem initium habebant mensibus Julio, Augusto et Septembri anni 1914, atque statim curavimus Sanctitatem Tuam de omnibus certiorem reddere; ac magno cum nostro solatio et laetitia pervenerunt Tuae litterae diei 25 Oct. mihi quidem, sed pro omni Episcopatu directae; dein praecipue quas plenas benevolentiae et officii die 25 Nov. eiusdem anni Episcopo Sancti Antonii Texas scribebas, ac denique missae Emo. Dno. Cardinali Gibbons die 17 Martii 1915. Nostram tamen agendi rationem a Te, Beatissime Pater, probari pergrato animo sensimus in Tuis litteris ad Episcopum Sancti Antonii memoratis, per illa verba. Interim hoc nunties velimus archiepiscopis atque episcopis iisdem, satis eos officii muneribus, satis suis gregibus esse facturos, si id fecerint quod tempora siverint; Nosque, absentes corpore, praesentes illis esse paterno animo ac preces plurima, qua misericordiarum Patrem et Deum totius consolationis instanter obsecramus, ut cum ipsis sit in tribulatione, aquí una vida miserable y llena de penalidades, también por los deseos de vez en cuando manifestados de gente proba, de que ahí permanezcan.

Todas estas cosas tuvieron su comienzo en los meses de julio, agosto y septiembre de 1914 e, inmediatamente, tuvimos cuidado de informar cabalmente a Vuestra Santidad; y con gran consuelo y alegría nos llegaron vuestras letras del 25 de octubre, dirigidas a mí, pero también a todo el Episcopado; después, principalmente aquéllas llenas de benevolencia y preocupación del 25 de noviembre del mismo ańo escritas por Vos al obispo de San Antonio y, finalmente, las que enviásteis al Eminentísimo Señor Cardenal Gibbons, el 17 de marzo de 1915. Con agradecimiento sentimos que nuestra manera de actuar había sido aprobada por Vos en vuestras letras al obispo de San Antonio ya recordadas. Entre tanto, quisimos que arzobispos y obispos hicieran lo que los tiempos les dejaran hacer, tanto por cumplir con los cargos de su oficio como por su grey, de modo que, ausentes en el cuerpo, les estuviéramos presentes con ánimo paternal y muchas oraciones, con las que suplicamos al Padre de las 
detque benignus, ut restituta quamprimum pace, suo quisque reddatur gregi et in novitate spiritus Deo servire pergat.

Episcoporum etiam absentiam clerus ac populus fidelis probarunt, et commendarunt usque ad praesens; Episcopi ipsi licitam immo necessariam censuerunt, ut etiam fideles a vexationibus liberarent, praesertim circa pecuniarias exactionibus, quas vidimus Episcopis impositas.

Perdurantque vero hac nostra absentia, nihil intentatum reliquimus ad hoc denuo in Patriam revertamur. Statim nempe ac dux Carranza ut talis agnitus fuit a Gubernio Statum Foed., Archiepiscopus Mechoacanensis, mensi octobri an. 1915, nomine et auctoritate caeterorum Episcoporum, Washingtoniam petiit apud ipsum Carranzae Oratorem de nostro regressu agens: ipsum $\mathrm{Ca}$ rranza, respondit, adendum, habita eius venia, quod adhuc desideratur.

Episcopus de Saltillo Carranzam invisere curavit mense nov- misericordias y Dios de toda consolación, que esté con ellos en la tribulación y conceda benigno que, restituida cuanto antes la paz, cada uno pueda tornar a su grey y servir a Dios con un espíritu renovado.

También el clero y el pueblo fiel aprobaron la ausencia de los obispos, y los encomiendan hasta el presente; los mismos obispos la consideraron lícita e incluso necesaria para que los fieles se vieran libres de vejaciones, especialmente de las extorsiones pecuniarias que se venían imponiendo a los obispos.

Pero durante todo el tiempo que ha durado nuestra ausencia, no hemos abandonado ningún intento para regresar a la patria, y lo seguimos intentando. Pues al punto que Carranza fue reconocido por los Estados Unidos como jefe del gobierno, el arzobispo de Michoacán, en octubre de 1915, en nombre de los demás obispos, pidió a Washington que intercediera por nuestro regreso ante el embajador de Carranza. Respondió el mismo Carranza diciendo que podríamos hacerlo una vez que tuviéramos la venia, lo cual hasta ahora estamos deseando.

El obispo de Saltillo invitó a Carranza en noviembre de 1915 a 
embri 1915 in pago mexicano "Nuevo Laredo", sed ad colloquendum non admissus, admonitus fuit in scriptis afferenda negotia pertractanda. Re itaque in scriptis perfecta, resposum a Carranza accepit (Doc. num. 2) per quem significatum ipsi fuit quod Episcopi, utpote politici emigrati, legem generalem amnistiae expectare permitatur. De hac amnistiae lege non semel Carranza publice declaravit se illam laturum postquam nova Reipublicae fundamentalem legem condiderit, novum gubernium constituat ac pleno pacis generalis subsidio fruatur (doc. num. 3).

Vir autem quidam catholicus e coetu diplomatico, qui exteram quandam Nationem Oratoris officcio Mexici repraesentat, sponte sua de episcoporum reditu cum Carranza egit mense Ianuario huius anni. Rationem autem reddens de huiusmodi Episcopo Aguascalientes in epistola (doc. num. 4) asserit nihil favoris aut gratiae alios Episcopos deprecatur, ut prorsus a reditus cogitatione interim abstineant.

Absentia ergo Episcoporum non eis est imputanda. Clerus ac fidelis populus quoad fieri potest de hisce ombnibus certiores sunt, dialogar en suelo mexicano, en Nuevo Laredo, pero no le fue permitido conferenciar, sino que se le advirtió que tratara por escrito los negocios que quisiera. Puesto el asunto por escrito, recibió respuesta de Carranza (Doc. núm. 2) en la que se le decía que él mismo y los demás obispos debían esperar una ley general de amnistía, pues su calidad era de refugiados políticos. De esta ley de amnistía Carranza ha mencionado varias veces que será tratada en cuanto se tenga la nueva Constitución de la República, se constituya el nuevo gobierno y se disfrute de condiciones de una paz generalizada (doc. núm. 3).

Cierto personaje católico del cuerpo diplomático, que representa a México en una nación extranjera, por cuenta propia habló con Carranza sobre el regreso de los obispos en enero de este año. En la razón que da sobre este asunto en carta al obispo de Aguascalientes (doc. núm. 4), asegura no haber conseguido ningún favor o gracia para los restantes obispos, para que se abstengan absolutamente de pensar en su regreso.

Por tanto, no se puede culpar a los obispos de su ausencia. El clero y el pueblo fiel son muy conscientes de que hicieron cuanto pudie- 
aliunde vero nemo ex nostris sacerdotibus ac fidelibus nescit quod religiosa persecutio eadem ac antea adhuc perseverat; decreta enim impia in dies singulos eduntur, sacerdotes identidem hac illac carcere et exilio puniuntur (doc. num. 5) ut in dioecesibus de $\mathrm{Yu}$ catan, Campeche et Tabasco paucis abhinc mensibus omnes sacerti expulsi; idem ferme in Campeche et Tabasco, ac nuper ex aliqua dioecesi nordica plures transierunt asportati per urbem Aguascalientes: ubique autem gravissimis minis terrentur, omnia Ecclesiae bona quaeruntur ac diripiuntur: quoad data es lex cum effecto retroactivo prohibens clericis capacitatem dominii, atque statim applicationem habuit: gravissimis sacrilegiis in res et personas sacras fidelium animi contristantur adhuc: alicubi, ut Guadalajarae nuperrime accidit, septem templa in usus prophanos convertuntur; religiosam instructionem clandestine habitam atrociter insectantur, suppressis iam scholis tum iis quae Ecclesia alebat, tum quae privatorum curae erant. ron y, de otra parte, ninguno de nuestros sacerdotes y fieles desconoce que la persecución religiosa que hay ahora es la misma que hubo antes: cada día se expiden decretos impíos, sin cesar los sacerdotes son remitidos a la cárcel o al exilio (doc. núm. 5), como en las diócesis de Yucatán, Campeche y Tabasco, de las que hace pocos meses fueron expulsados todos los sacerdotes y, lo mismo que en Campeche y Tabasco, de una diócesis del norte muchos fueron obligados a irse a Aguascalientes y ahí, aquejados por graves amenazas, fueron requisados todos los bienes de la Iglesia, ya que se promulgó una ley con efecto retroactivo que prohibía a los clérigos la capacidad de poseer algo, y fue aplicada inmediatamente, lo que conllevó gravísimos sacrilegios en las personas y cosas sagradas que contristan todavía ahora el ánimo de los fieles. En alguna parte de Guadalajara ocurrió recientemente algo parecido: siete templos fueron entregados para usos profanos, la instrucción religiosa, que se impartía en la clandestinidad, fue rabiosamente perseguida, $y$ han sido suprimidas tanto las escuelas auspiciadas por la Iglesia como las que eran dirigidas por particulares. 
Statim post receptionem litterarum Excmi. Delegati Apostolici, Episcopus de Zacatecas in Patriam rediit, nomine et dignitate prorsus celatis; sed acceptis eius litteris, constat ipsum nullo modo potuisse se conferre in suam episcopalem civitatem, aut in aliquem pro diocesis administratione convenientem pagum, sed per montes vagare teneri nec dioecesim, quod hic aliqua ratione ipsis fas erat, ullo modo administrare posse: et, quod maxime notandum est, in suis litteris artificiosa quadam ratione scriptis ac missis tum ad Episcopum de Guadalajara, tum ad Episcopum de Aguascalientes, quorum dioeceses partim percurrere debuit, enixe rogat ut a remeandi sentential omnes prorsus Episcopi adhuc desistant (doc. 6.).

Archiepiscopus de Guadalajara, qui nuper Roma huc pervenit, maga et confisa voluntate iter in Mexicum prosequendi, falsis aut detortis notitiis allectus, litteras obsequio plenas statim accepit ex omni hominum coetu tum plenas moerore ex eo quod Romam reliquisset, tum anxietate, quibus monetur de gravissimis perturbationibus, quibus ansam praeberet ex suo in Mexicum ingressu, ac de
Inmediatamente después de recibir las letras del Excmo. Señor Delegado Apostólico, el obispo de Zacatecas regresó a la patria, ocultando, desde luego, su nombre y dignidad; pero aun habiendo recibido sus letras, consta que él no pudo en manera alguna instalarse en su sede episcopal, ni en algún otro lugar de la diócesis conveniente para administrarla, sino que tuvo que vagar montes, y ni siquiera de su diócesis, que de ningún modo pudo administrar, lo que informó de alguna manera y, lo que es más de destacarse, en cartas cifradas que envió tanto al obispo de Guadalajara como al de Aguascalientes, cuyas diócesis parcialmente estaba recorriendo, suplicó encarecidamente que todos los obispos por el momento desistieran de regresar (doc. núm. 6).

El arzobispo de Guadalajara, quien recientemente llegó aquí procedente de Roma, con firme resolución de continuar su camino hacia México, incitado por noticias falsas o distorsionadas, inmediatamente recibió unas cartas llenas de adulación que procedían de una junta de todo tipo de personas, en las que se lamentaban de que hubiera abandonado Roma y se le advertía de las graví- 
suo personali periculo certo mortis: ac folia publica mexicana, quae omnia Carranzae morem gerunt, animos excitare coeperunt in ipsum et in Ecclesiam. (doc. num. 7).

Circa accusations vero in Episcopos allatas, ac continuo iterates, necnon de novis in dies contumeliis et calumniis a Carranza eiusque asseclis public exhibitis, haec habeo animadvertenda.

Certo certius haec Revolutio, socialisticam publicae rei reformationem et restaurationem intentans, ut id plene attingatur, per vim et nefas omne subverso omni ordine, Religionem ipsam persequi statuit, si fieri possit, usque ad interncecionem $[s i c]$. Hoc dilucide patet ex illius fautorum scriptis, tum officialibus, itemque ex ipsorum dictis coram testibus omni fide dignis, ex eorum agendi ratione, ab initio usque adhuc protracta et servanda usque ad plenam Revolutionis et huius Gubernii constitutionem. Haec Omnia dilucide apparent in doc. num. 8.

Quidquid igitur Episcopi egerint vel quomodocumque se simas perturbaciones que ocasionaría su ingreso a México, con lo que correría un peligro cierto de muerte. Además, con volantes públicos de los que acostumbra, la gente de Carranza, comenzó a excitar los ánimos en contra suya y de la Iglesia (doc. núm. 7).

Empero, sobre las acusaciones levantadas contra los obispos y continuamente reiteradas, así como de los nuevos ultrajes y calumnias procedentes de Carranza y sus secuaces y públicamente recibidas, debo hacer las siguientes advertencias.

Es más que cierto que esta Revolución socialista, buscando la reforma y la restauración de los asuntos públicos, como consta plenamente, a través de la violencia y de la subversión nefasta de todo el orden, ha establecido perseguir la religión hasta extinguirla, si fuera posible. Esto claramente se aprecia a partir de los escritos de los promotores de la Revolución, tanto oficiales como de lo que han dicho ellos mismos ante testigos dignos de toda fe, así como de su misma actuación, desde el principio y mantenida hasta ahora con el triunfo pleno de la Revolución y de su Gobierno. Todo esto aparece claramente en el doc. núm. 8 .

Cualquier cosa que los obispos hayan hecho, o el modo en 
anteacto tempore gesserint, id omne ansam praebet nefariis iis hominibus sinistrae interpretationis atque insectationis: haec tamen locum non habuissent nec habebunt, si ipsi Episcopi ab officio suo defecissent et principia revolutionis sectentur, quod Deus avertat.

Inde, nempe ex condicio hoc in Ecclesiam singulari bello, proveniunt omnes et singulae calumniosae assertationes de episcoporum interventu in rebus politicis, de communi eorum cooperatione in evertione Praesidis Madero, de auxilio materiali Praesidis Huertae oblato, de conspirationibus contra Carranzae factionem, de promotione interventus Americanae Confederationis ad pacem Mexicanae Republicae restituendam et alia huiusmodi; quibus mediis nunc illi utuntur ut odium concitent in Ecclesiam et Clerum.

De actione Episcoporum in re polytica: Compertum mexicanis omnibus est quod, invitante D. Madero, cives omnes in iura sua politica vindicanda et exercenda, catholici viri non pauci aggressi sunt efformationem consociationis polyticae seu Conventus, sub nomine "Partido Católico". Id autem maior pars Episcoporum probavit, publicis datis documen- que anteriormente lo hacían, todo esto ha servido a estos hombres nefastos para sacar motivo de ultrajar y perseguir; sin embargo, estas cosa no hubieran tenido, ni tendrían ahora lugar, si los obispos mismos hubieran traicionado su oficio y seguido los principios de la revolución, que Dios nos libre.

Pues, a partir de ahí, de este singular combate que se sigue contra la Iglesia, proceden todas y cada una de las afirmaciones calumniosas: de la intervención de los obispos en los asuntos políticos, de la cooperación en la revuelta contra el presidente Madero, de la ayuda material ofrecida al presidente Huerta, de promover una intervención armada de los Estados Unidos para restablecer la paz en la República Mexicana y otras por el estilo, medios que ellos utilizan ahora para exaltar el odio contra la Iglesia y el clero.

Sobre la actuación de los obispos en asuntos de política, es completamente conocido por todos los mexicanos que, habiendo sido invitados por el señor Madero todos los ciudadanos a que ejercieran y reinvindicaran sus derechos políticos, no pocos católicos se dieron a la tarea de conformar una asociación o partido político con el nombre de Partido 
tis, ut eorum actio distincte a rebus polyticis se iungeretur. Madero ipsi gratissimum hoc accidit, ac officiali documento hunc Conventum polyticum catholicorum civium, ut primum salutarem fructum suae restaurationis socialis agnovit, ac per documentum Schema ipsum Conventus approbavit.

SANCTA SEDES a me interrogata approbavit constitutionem huiusmodi Conventus, eiusque Schema, necnon titulum ipsum "PARTIDO CATÓLICO NACIONAL": ut constat ex documentis proborum virorum.

DELEGATUS APOSTOLICUS, Excmus. D. Boggiani, pluribus episcopis commendavit huiusmodi, ac litteras laudatorias scripsit Archiepiscopo Mechoacanensi de eius opera circa huiusmodi.

Actio autem Episcoporum, habita in re polytica, fuit de consensu et consilio $S$. Sedis, et huiusmodi actio, ut ex documentis constat, hisce limitationibus continebatur:
Católico. Éste fue aprobado por la mayor parte de los obispos, una vez que fue reconocido públicamente, para que su actuación no quedara ligada a los asuntos políticos. Gran beneplácito causó a Madero mismo y, en un documento oficial, reconoció al partido político integrado por ciudadanos católicos como el primer fruto saludable de su restauración social y, a través del mismo documento, aprobó el Programa del Partido.

LA SANTA SEDE, interrogada por mí, aprobó la constitución de tal partido, así como su Programa e incluso el mismo nombre de PARTIDO CATÓLICO NACIONAL, como consta a partir de documentos de personas confiables.

El DELEGADO APOSTÓLICO, Excelentísimo Señor Boggiani, lo recomendó igualmente a muchos obispos y escribió cartas laudatorias al arzobispo de Michoacán en este mismo sentido.

Así pues, la actuacion que los obispos hayan tenido en asuntos de política fue del conocimiento y en común acuerdo con la Santa Sede, y en acciones del mismo tipo, como consta a partir de varios documentos, sólo se señalaban las siguientes limitaciones: 
1 Principia catholica exhibebant circa actione polyticam civium catholicorum excerpta ex Encyclicis Litteris aliisque documentis Leonis XIII ac Pii X.

2 Schema circa intenta ac desiderata Conventus Catholici approbarunt.

3 Enixe insisteban circa damnatum principium Rebelionis, circa vitandas publicas perturabationes, prudentiam in iuribus vindicandis.

Simul plenam catholicis libertatem relinquebant in actionibus mere polyticis, circa candidatorum praesentationem, eorum electionem, necnon circa polyticas omnes controversias, in quibus de principiis ipsis circa originem, scopum atque extensionem Auctoritati non agebatur.

Haec catholicorum ac Episcoporum actio ab ipsa Mexicana fundamentali agnoscitur ut licita, nec acatholici ipsi, quamvis plura in catholicos effutiebant, nunquam illam actionem quasi legibus contrariam impetebant. Ac Carrancistae, ad persecutionem cohonestandam, clerum mexicanum nunc accusant quasi contra leges nationales egissent: eodem iure ac aristocratiam omnem
1 Que se tomen en cuenta los principios sobre la actuación política de los ciudadanos extraidos de las encíclicas y de otros documentos de León XIII y Pío X.

2 Que los obispos aprueben el programa de propuestas y aspiraciones del Partido Católico.

3 Que insistan con empeño en que está condenado el principio de rebelíón, en que se deben evitar las perturbaciones públicas y en que se debe de tener prudencia en cualquier reivindicación.

$\mathrm{Al}$ mismo tiempo, que se les diera libertad plena a los católicos en acciones meramente políticas, en la presentación de candidaturas, así como en otras controversias políticas, en las cuales la Autoridad (episcopal) no interviene ni en el origen, ni en el objetivo, ni en la extensión de esos principios.

Esta actuación de los católicos y del episcopado fue reconocida como lícita por la Constitución Mexicana, pero no así por los acatólicos, quienes aunque decían muchas tonterías en contra de los católicos, nunca demostraron que su actuación fuera contraria a las leyes. Y ahora los carrancistas, para cohonestar la persecución, acusan al clero mexicano como si hubiera actuado en contra de las 
mexicanam accusant, ad direptionem socialisticam sanciendam et tuendam, quasi illicite suas divitias congessisset per quattuor saecula.

Dnus. Aloysius Cabrera, hodiernus aerarii publici moderator et Minister apud Carranza, quique intellectualis anima huius socialisticae Revolutionis existit, atque antea amicitiae necessitudine cum celebri Ferrer nimis divinctus, in opusculo suo edito ad proposita Revolutionis propugnanda, claris verbis statuit ea illuc tendere, ut Ecclesiam omni privet influxu, quem in populum catholicum habet, omniaque media licere sibi ut scopum hunc adipiscatur.

In Gubernii Dni. Madero eversione, nec Episcopi, nec Clerus, nec catholici ullo modo complicitatis crimine arguendo sunt: imo publico document Episcoporum, mense ianuario anni 1913, uno mense ante illius evertionem, constat quod ipsi rebellionem et conspirationem contra Madero condemnassent; nam rumor ad eos pervenerat de intentata subversione, ineter cuius conspiratores duo ex praecipuis leyes nacionales; con el mismo régimen legal acusan a toda la aristocracia mexicana, con el fin de aprobar y proteger el saqueo socialista, de haber amontonado ilícitamente sus riquezas durante cuatro siglos.

El señor Luis Cabrera, actualmente administrador del erario público y ministro con Carranza, quien es el alma intelectual de esta Revolución socialista, y que ya antes había sido cautivado por su relación de amistad con Ferrer, en un opúsculo suyo publicado para propagar los objetivos de la Revolución, con expresiones claras estableció aquellas cosas que ésta pretende: privar a la Iglesia de toda la influencia que tiene entre el pueblo católico, para lo cual habría que hacer uso de cualquier medio que esté al alcance.

En la revuelta contra el gobierno del señor Madero, ni los obispos ni el clero pueden ser acusados de complicidad en la planeación del crimen, lo que por cierto consta en un documento de los obispos, del mes de enero de 1913, un mes antes de la subversión, en el que ellos mismos condenaron la rebelión o conspiración contra Madero, pues les había llegado rumor de que se buscaba rebelarse y, entre los conspiradores, había dos 
viris cahtolici Conventus recensebatur. Atque equidem pridie adhuc quam Madero subverteretur, catholicus Coetus polyticus de Michoacan, de consensu Archiepiscopi, proclamationem edidit rebellionem in Mexicana Civitate concitatam improbans.

Episcopi ac Clerus arguuntur quia Dnum. Huerta tanquam legitimum Reipublicae Moderatorem agnoverunt. Sed equidem nullo modo ad episcopos et clerum pertinet hac de re sententiam ferre: coetus nempe Deputatorum ac Senatorum, Gubernatores provinciarum, duobus exceptis, imo Gubernis Europae aliarumque orbis partium, ipsum fere omnia agnoverunt. Si qua culpa hic habetur, culpa fuit eorum quibus ex lege incumbit rem hanc trutinam revocare; nulla Episcoporum ac Cleri.

De pecunia exhibita Dno. Huertae non semel episcopi declararunt nihil omnino eos dedisse; neque aliunde vel minimam probationem accusatores exhibuerunt. Hoc certe verum est, me 17 millia Mexicana argentea commodasse Dno. Huertae, sed nullo modo pro conspiratione, insignes miembros del Partido Católico. Y, también es cierto que, antes todavía de que se diera la rebelión contra Madero, el Partido Católico de Michoacán, de común acuerdo con el arzobispo, publicó una proclama condenando la rebelión suscitada en la ciudad de México.

Argumentan también que los obispos y el clero reconocieron al señor Huerta como legítimo presidente de la República. Ante esto, cabe decir que de ningún modo es competencia del clero y de los obispos reconocer si un presidente es legítimo o no; en cambio, las cámaras de Diputados y de Senadores, los gobernadores de los estados, salvo dos excepciones, incluso los gobiernos de Europa y de otras regiones del orbe, casi todos sí lo reconocieron. Si alguna culpa existe aquí, la culpa fue de aquéllos a quienes por ley incumbe aprobar y juzgar estos asuntos, y no de los obispos ni del clero.

Sobre el dinero ofrecido al señor Huerta, varias veces los obispos declararon que ellos absolutamente nada le habían dado, y por ningún lado los acusadores aportaron ni mínima prueba. Aunque sí es verdad que yo mismo presté al señor Huerta 17,000 pesos de plata, mas no para la conspiración, sino 
sed ea iam consumata, pro militum stipendiis, quae nisi statim soverentur, timendum erat ne urbs diripetur a militibus. Paratus sum rem ita ac non aliter se habuisse, coram Apostolica Sede ad normam iuris declarare et probare. Rumor autem calumniosus de meo auxilio prestito Dno. Huertae iam ante revolutionis triumphum Mexici de ore in os ferabatur: ac, quod mihi magis dolendum est, Excmus. Delegatus Apostolicus suspectum saltem me de hoc habuit. Praesumptione fortasse aliquae in me afferentur, ex necessitudine praecipue mea cum Praeside Conventus Catholici, aque ex eius verbis et factis. Opus ego hoc iure merito tribuo Reverendo Dno. Paredes, cuius informationes precor cum magna cautela suscipiantur in Romana Curia, semper ac de iis rebus agatur.

Nullam denique nos habere partem in comminato Interventu Americanae Foderationis quoad Mexicanam Rempublicam fideles nostrarum dioeceseon certo certius sciunt, etsi folia socialistica mexicana aliter clament, Dnum. Wilson qui Carranzam in suum nefandum opus omni ope adiuvit et adiuvat, necnon Carranzam ipsum, plures habere secretos in-
- habiéndose ésta consumadopara pagar el sueldo de los soldados, que si no hubiera sido pagado inmediatamente, se temía que la ciudad fuera saqueada por los soldados. Estoy preparado para, si hace falta, probar ante la Sede Apostólica que actué así, y no de alguna otra manera. Pues, un rumor calumnioso de mi auxilio prestado al señor Huerta corrió de boca en boca ya antes del triunfo de la revolución y, lo que más me duele, es que el entonces Excelentísimo Señor Delegado Apostólico al menos haya tenido sospechas de mí. Quizá por alguna presunción que le llegó en contra de mí junto con el presidente del Partido Católico, y de sus palabras y obras. Lo cual atribuyo al Reverendo Señor Paredes, cuyas informaciones suplico sean recibidas en la Curia Romana siempre con gran cautela, y de igual forma se actúe.

Finalmente, tampoco tenemos parte alguna en la amenaza de intervención [armada] de los Estados Unidos en México, lo que los fieles de nuestras diócesis perfectamente saben, aunque los folletos de inspiración socialista lo difundan de otra manera. El señor Wilson, quien ha ayudado y continúa ayudando a Carranza en su nefasta obra, así como el mis- 
vestigatores per totum hoc Foederatorum Statuum territorium dispersos, qui certe testificantur Episcopos nihil de interventu nil de eversione Carranzae moliri. Si quid enim episcopi vel mínimum egissent, libentissime D. Wilson aut Carranza occasiones arripuisent eos ad tribunalia traducendi; ut egerunt ut Dno. Huerta. Sed e contra Carranza in poenultima suae officiali notificatione nonnihil contra Clerum indicavit de hisce, quae autem nullum meruerunt responsum ex parte Gubernii Statuum Foederatorum. Imo impius coetus huius nationis dictus "The Guardians of Liberty" formalem exhibuit accusationem de quadam conspiratione contra Carranzae Gubernium inita ab Emo. Cardinali Gibbons ac nonnullis episcopis mexicanis; Deputatorum autem publicus coetus hius Nationis nec verbum quidem respondendum censuit accusationi exhibitae: ipsa tamen vernacula lingua, sed sin data anni, mensis et diei, nunc in vulgus editur, ad excitandos animos (doc. num. 9).

Rogo ergo SANCTITATEM TUAM, omni qua par est reverential et obsequio, omnem profi- mo Carranza, tiene espías dispersos por todo el territorio de los Estados Unidos, que ciertamente son testigos de que los obispos no intrigan ni acerca de una intervención, ni de la revuelta de Carranza. Si algo, aunque fuera mínimo, en relación con estos temas hubieran hecho los obispos, habría servido para que Wilson o Carranza con muchísimo gusto los llevaran ante los tribunales, como lo hicieron con Huerta. Mas, en cambio, Carranza en su penúltima notificación oficial nada dice de esto en contra del clero y estas acusaciones tampoco merecieron respuesta alguna del gobierno estadounidense. Por el contrario, un impío grupo de esta nación, autoproclamado "El guardián de la libertad", presentó una acusación formal de cierta conspiración contra el gobierno de Carranza, iniciada por el Eminentísimo Cardenal Gibbons y algunos obispos mexicanos; sin embargo, la Cámara de Diputados de esta nación ni siquiera dijo nada sobre la acusación presentada, la cual no obstante fue publicada sin ninguna fecha en lengua vernácula para caldear los ánimos (doc. núm. 9).

Suplico, pues, A VUESTRA SANTIDAD, confesando toda mi devoción y obediencia A LA 
tens APOSTOLICAE SEDI devotionem et obedientiam, ut, si quid contra Mexicanos Episcopos ad aures TUAE SANCTITATIS pervenerit, delatum vel a pravis clericis, vel ab aliis incauto deceptis, quod nonnihil minuerint TUAM enim benevolentiam et existimationem, prorsus abicias: quod, si eveniet, nobisque constet, hoc magnum solaium [sic] afferent nostris aerumnis quae nimis animos labefactant.

Quod Deus \&.

SANCTI ANTONII TEXAS, die 5 Augusti anni MCMXVI.

[escrito ya a mano] Sanctitatis Tuae humillimus servus
SEDE APOSTÓLICA, que, si algo contra los obispos mexicanos llegara a los oídos DE VUESTRA SANTIDAD, procedente ya sea de clérigos depravados o de personas incautamente engañadas, que en manera alguna habrán de hacer disminuir vuestra benevolencia y lo alejéis decididamente de vuestra estimación y, si ocurriera, nos lo hagáis constar, lo cual atraerá un gran consuelo en medio de nuestras tribulaciones que tanto debilitan nuestros ánimos.

Que Dios...

En San Antonio, Texas, el día 5 de agosto del año de 1916.

Siervo humildísimo de Vuestra Santidad,
[Rúbrica]
+Joseph,

Archiepus. Mexicanus

Reformas que pretende la Revolución: ${ }^{6}$

1. Enseñanza. La enseñanza primaria y normal será monopolio del Gobierno.

2. La enseñanza primaria será obligatoria, gratuita y laica para niños y niñas.

3. Las escuelas profesionales serán intervenidas por el Gobierno Federal, quien será el que precise los requisitos conforme a los cuales deben expedirse los títulos.

4. Los profesores serán inamovibles.

\footnotetext{
${ }^{6}$ Se encuentra después de la firma, como corolario del documento, y sólo en español.
} 
5. Las personas dependientes de asociaciones religiosas no podrán dedicarse a la enseñanza.

6. No se tolerarán seminarios religiosos.

7. No se tolerarán escuelas dependientes de Asociaciones Religiosas.

1. Religión. No se tolerarán asociaciones dependientes de Asociaciones Extranjeras.

2. No se permitirá que los encargados de los servicios religiosos tengan como único medio de subsistencia la caridad pública.

3. Los sacerdotes católicos y los miembros de algún otro culto religioso no tendrán derecho a votar ni a ser votados.

4. No se tolerará el celibato en las personas encargadas de servicios religiosos.

5. No se tolerará la confesión.

6. No se permitirá que tengan lugar cultos religiosos en los días y horas de trabajo.

7. Habrá un Interventor del Gobierno que vigile por el uso de las limosnas recogidas para el fomento de las instituciones religiosas.

Reformas sociales. El Divorcio \&\&\&.

Consúltese: Religión:

Manifiesto de Carranza de 11 de julio de 1915.- Comunicado de L. Cabrera, mayo 15/15.- Intervención en la administración de Sacramentos; Decreto del Gobierno de Hidalgo, dic. 1914.- Inventarios; Decr. del Gobierno de Aguascalientes, dic. 22/15.- Id. de Michoacán, de Hidalgo, \&.- Intervención en el culto: Decr. del Gob. de Nuevo León, 1914, de Tlaxcala 18 de Nov 1915.- Id. del de Toluca, del de Yucatán 1914.

Instrucción: Ley de Agosto 14/15., Nov. 16/15. Guanajuato, Agto. de 1915.- Id. de Michoacán.

\section{Epílogo}

Hay documentos que hablan de tal modo por sí mismos que prácticamente no hace falta comentarlos. Es interesante, sin embargo, señalar que en pocos de ellos se puede conseguir una visión tan am- 
plia y documentada de lo que ocurrido en la etapa preconstitucionalista con los obispos mexicanos.

Existe, también en el Archivo de la Arquidiócesis de Guadalajara, otra carta mucho más breve del arzobispo de Morelia, Leopoldo Ruiz y Flores, ${ }^{7}$ que guarda cierto parecido con la recién comentada. Esta última escrita no para ser entregada al romano pontífice, sino para informar a Orozco de la situación en México y él sirva como canal para hacer llegar estos datos al papa. En ella, el obispo Ruiz desconfía de que Mora haya informado puntualmente a la Santa Sede y por eso recurre a los buenos oficios de Orozco y Jiménez para mantener informado a Benedicto XV. La mayor coincidencia de esta última con la que hemos transcrito estriba en que también llegó a Roma cuando el arzobispo de Guadalajara había regresado y se encontraba ya en territorio americano. ${ }^{8}$

El tono de ésta no es muy diferente al de la de Mora y nos sirve tener a la vista algunos fragmentos para establecer paralelismos. Por ejemplo, en relación con la actitud de fondo del gobierno, señala que "Carranza y los suyos han continuado sistemáticamente sus actos de hostilidad con el fin de debilitar y si fuera posible destruir todo lo que es culto, sacramentos, instrucción religiosa y religión". ${ }^{9}$

Entre éstos, le preocupaban especialmente los que reducían de manera arbitraria el número de sacerdotes que podían ejercer su ministerio:

${ }^{7}$ Leopoldo Ruiz y Flores nació en Amealco, Querétaro, en 1865. Cuando apenas contaba con 35 años fue nombrado obispo de León, después, de Linares y, finalmente, de Morelia. Durante el gobierno de Madero promovió la participación de los católicos en la vida pública. Refugiado en los Estados Unidos a causa de la Revolución, en los primeros meses de 1917 coordinó en aquel país la redacción de la Pastoral Colectiva con la que los obispos protestaron contra algunos artículos de la Constitución de 1917 que atentaban contra la libertad religiosa. En 1926 fue designado vicepresidente del Comité Episcopal presidido por Mons. Mora y del Río. En 1927, nuevamente tuvo que exiliarse. Viajó a Roma a principios de 1929 para acelerar la llegada a un acuerdo con el gobierno mexicano que permitiera la reanudación del culto público. Fue delegado apostólico de 1929 a 1937; en este ańo, al ser nombrado delegado apostólico Mons. Luis Ma. Martínez, don Leopoldo Ruiz y Flores regresó como arzobispo a la arquidiócesis de Morelia, donde murió en 1941 (cfr. Juan González Morfín, Los obispos, 45-56).

${ }^{8}$ Cfr. Leopoldo Ruiz y Flores, Carta a Francisco Orozco y Jiménez, 1-vI-1916, en AAG, sección gobierno, serie obispos: Francisco Orozco y Jiménez, correspondencia.

${ }^{9} \mathrm{Ib}$. 
V.S.I. estará al tanto de todos los atropellos y sacrilegios últimamente cometidos en Yucatán, Guadalajara, Sonora, etc. El gobernador de Michoacán dio orden el 4 de mayo de que salieran del Estado todos los sacerdotes de Morelia, debiendo quedar solamente uno para cada dos templos. Gracias a que el pueblo se mostró indignado no se llevó a cabo ese decreto, pero hay temores de que de un momento a otro se lleve a efecto. ${ }^{10}$

Con algunos matices diferentes, menciona una cierta campaña orquestada por Carranza y su gente para desprestigiar a los obispos:

Por otra parte Carranza se ha propuesto desacreditar a los obispos y clero mexicanos, tanto en México como aquí en los Estados Unidos. Por un lado nos niega la entrada a México, como consta por mis gestiones con Arredondo en Washington y la respuesta dada al Sr. Echavarría; y por otra sus periódicos en México están diciendo que no volvemos a México porque no queremos.

Y agrega que, para desprestigiarlos en los Estados Unidos, Carranza insiste en que "estamos promoviendo revoluciones y que somos partidarios de la intervención americana”. ${ }^{11}$

Después de hablar de la posibilidad, también abordada por Mora de un cisma, volvía a su petición de que estos datos debían ser conocidos por la Santa Sede y sugiero como intermediario a Mons. Boggiani. ${ }^{12}$ Estos documentos, junto con un percepción personal de lo que estaba ocurriendo, aportan sobre todo un caudal de datos para comprender mejor lo que en esos momentos acontecía en el país.

\footnotetext{
${ }^{10} \mathrm{Ib}$.

${ }^{11} \mathrm{Ib}$.

${ }^{12}$ Tommaso Boggiani, quien había sido delegado apostólico en México entre 1912 y 1914.
} 